\title{
ESTEREOTIPOS DE GÉNERO Y MATRIMONIO REGIO COMO ESTRATEGIA DE LEGITIMACIÓN EN LA MONARQUÍA ESPAÑOLA CONTEMPORÁNEA*
}

\section{STEREOTYPES OF GENDER AND REGAL MARRIAGE AS STRATEGY OF LEGITIMACY IN CONTEMPORARY SPANISH MONARCHY}

\author{
Alicia Mira Abad \\ Universidad de Alicante
}

\begin{abstract}
SUMARIO: I. INTRODUCCIÓN - II. TRANSFORMACIONES EN LOS FUNDAMENTOS LEGITIMADORES DE LA MONARQUÍA - III. EL MATRIMONIO REAL EN LA NARRATIVA LEGITIMADORA - 3.1. Alfonso XIII: Una masculinidad en construcción - 3.2. Victoria de Battemberg: el envoltorio moderno para la feminidad tradicional - IV. CONCLUSIONES
\end{abstract}

Resumen: Este estudio es una aproximación al proceso de difracción que experimenta la legitimidad monárquica en contacto con las nuevas estructuras del Estado liberal. La faceta carismática de las figuras regias adquiere así gran importancia desde la perspectiva de las representaciones y su percepción como fuente de poder. Desde Amadeo de Saboya, pero especialmente con Alfonso XIII y Victoria de Battemberg, la construcción de estereotipos de género $\mathrm{y}$ su escenificación es utilizada como instrumento destinado a reforzar una legitimidad que combina tradición y modernidad. La pareja real se convierte así en referente familiar y garantía de regeneración nacional.

\begin{abstract}
This study is an approach to the process of diffraction that experiences the monarchic legitimacy in touch with the new structures of the liberal State. In this way, the charismatic facet of the royal figures acquires great importance from the perspective of the representations and its perception as source of power. From Amadeo of Saboya, but specially, with Alfonso XIII and Victoria of Battemberg, the construction of gender stereotypes and its reproduction is used as an instrument destined to reinforce a legitimacy that combines tradition and modernity. Thus the royal couple turns into familiar modal and guarantee of national regeneration.
\end{abstract}

Palabras clave: Monarquía, legitimidad, género, estereotipos, Alfonso XIII, Victoria de Battenberg

Key words: Monarchy, legitimacy, gender, estereotypes, Alfonso XIII, Victoria de Battenberg 


\section{INTRODUCCIÓN}

Entre el último tercio del siglo XIX y principios del XX las monarquías se transforman y adquieren un nuevo sentido como estructura de poder. Norberto Bobbio las describe como "una forma mixta, mitad monarquía, mitad república"1 para explicar un complejo proceso de relegitimación que busca representar a la nación en el marco de la soberanía nacional, a través de una dinámica que se mueve entre la seguridad y el progreso. Como señala Langewiesche, el XIX "es el siglo burgués, el siglo de la nación y del Estado nacional" pero también es el momento de la monarquía, "capaz de adaptarse, institucional y culturalmente", convirtiéndose en una "fuerza politica y cultural de integración"2. Este trabajo es una aproximación a las transformaciones que experimenta la legitimidad monárquica en su choque e integración en las nuevas estructuras del Estado liberal, a la consiguiente construcción de una faceta carismática de las figuras regias que combina tradición, modernidad y popularidad $\mathrm{y}$ por tanto, al resbaladizo campo de las representaciones y la construcción de estereotipos.

El reinado de Amadeo de Saboya y su esposa $\mathrm{M}^{\mathrm{a}}$ Victoria constituye un punto de inflexión en la proyección social de la monarquía, tras el proceloso reinado de Isabel II que no solo cuestionó los convencionalismos culturales burgueses sino que representó un peligro para la legitimidad de una institución que debía situarse por encima de las luchas partidistas, pero siempre sujeta a la voluntad soberana de la nación ${ }^{3}$. Su conducta fue considerada incompatible con los valores políticos y morales de una monarquía liberal, de manera que la figura del rey "demócrata" permitía neutralizar la mala imagen de la reina y proyectar una nueva forma de entender el papel de la monarquía. El rey Amadeo inicia en este sentido un camino que desarrollará plenamente Alfonso XIII.

Entre ambos reinados y en contextos históricos muy distintos, la gestualidad del individuo-rey es un recurso utilizado para compactar su imagen de primer ciudadano. $\mathrm{Y}$ junto al rey la figura de la reina, proyectada como modelo de comportamiento y sostén de la primera familia de la nación. Al igual que su antecesor italiano, el acceso de Alfonso XIII al trono se presenta como un soplo de aire fresco y renovador en el marco de un impulso de nacionalización de la institución apoyado por algunos políticos y militares. Según Moreno Luzón, ya con el inicio de la Restauración se buscaba construir una cohesión nacional que sumara a la trayectoria histórica de la nación española nuevas estrategias destinadas a aportar solidez al edificio nacionalizador ${ }^{4}$.

Tras el Desastre de 1898 la corona se presenta como una institución capaz de aglutinar las expectativas de cambio, siempre que lograra convertirse en referente identitario, construido sobre la idea de tradición, modernidad y

*Este trabajo se inserta en los proyectos de investigación "El discurso

1 Norberto Bobbio, Estado, gobierno y sociedad. Por una teoría general de la politica, Fondo de México, Cultura Económica, 1995, pp.125 y 149.

2 Dieter Langewiesche, La época del Estado-nación en Europa, Jesús Millán y M ${ }^{a}$ Cruz Romeo (eds), Universitat de València, Valencia, 2012, pp. 119-120.

3 Isabel Burdiel, "Edición y estudio introductorio" en SEM, Los Borbones en pelota, Institución "Fernando el Católico", Zaragoza, 2012, pp. 23 y 41.

4 Javier Moreno Luzón, "Hacer patria, defender la nación”, en J. Moreno Luzón (edit.), Izquierdas y nacionalismos, Pablo Iglesias, Madrid, 2011, pp. 88-90. 
regeneración propias de principios del siglo $\mathrm{XX}^{5}$. Hay que tener en cuenta que "la monarquía no soporta la derrota de una guerra que la nación haya interpretado como guerra nacional"" y desde luego la pérdida de los últimos vestigios coloniales frente a Estados Unidos se consideró un signo de degeneración nacional. Es por tanto, un momento especialmente critico en el que convergen varias líneas de pensamiento en torno a la definición de la identidad española: por un lado quienes adoptan una posición victimista, relacionada con una idea de decadencia generalizada de las razas latinas, que trasciende el caso español para presentar la superioridad de las razas protestantes anglosajonas y germanas sobre las católicas de sur ${ }^{7}$. Por otra, un resurgir nacionalista que busca precisamente en el interior, en las esencias del pueblo español, su referente ${ }^{8}$ y que en algunos casos aboga por un nuevo patriotismo cohesionador, cuyo objetivo es "reinventar" una España moderna y de progreso. Sin renunciar a la historia como anclaje cohesionador, Rafael Altamira propone otro horizonte nacional construido a partir de una "acumulación de intereses, riesgos, sensaciones, ideas, etc. con cierta unidad y solidaridad sociales, cristalizadas en un carácter común y una identidad colectiva" ${ }^{9}$, que muy bien podría representar un monarca joven y emprendedor.

Si el rey encarna a la nación, su figura como hombre debe representar un modelo de masculinidad heterogéneo en su composición, para reflejar distintas sensibilidades sociopolíticas, pero aparentemente homogéneo en su proyección social. En este contexto en el que bullen diversas propuestas en torno al "ser" de la nación, también se cuestiona el ideal masculino español frente al arquetipo viril anglosajón. No se trata de una crisis provocada por cambios en las relaciones de género, sino por una desvalorización del "hombre español" desde el extranjero, pero también desde el interior. La reconstrucción de la figura del rey como prototipo de hombre moderno que a su vez condensa toda la esencia española supone un intento de neutralizar la descalificación de la nación y acabar con un factor de inestabilidad en la configuración de la identidad nacional ${ }^{10}$. Así pues la boda del joven monarca con la princesa inglesa Victoria de Battemberg, nieta de la ejemplar reina Victoria y vinculada a un país y a un sistema politico con solera $\mathrm{y}$ prestigio, adquiere mucha importancia, no solo por su contribución a la construcción de unos estereotipos de género sobre los que proyectar comportamientos familiares y morales, sino porque ayudaba a fortalecer la imagen de un rey moderno identificado con su patria. Además el enlace fue interpretado como su verdadera mayoría de edad, teniendo en cuenta que empezó a reinar con 16 años. El matrimonio le convertía en potencial padre de familia, lo

5 Jesús Millán, María Cruz Romeo: "Modelos de monarquía en el proceso de afirmación nacional de España, 1808-1923”, en Diacronie. Studi di Storia Contemporanea, 16 (2013), p.2

6 Dieter Langewiesche, La época del Estado-Nación en Europa, op.cit., p. 21

7 Una línea que arranca con Cánovas del Castillo ante la "cuestión romana". Antonio Cánovas del Castillo, Discursos en el Ateneo, Obras Completas, Tomo I, Fundación Cánovas del Castillo, Madrid, 1981, pp.57-82

8 Lily Litvak, "Latinos y Anglosajones. Una polémica de la España Fin de siglo", en España 1900, Modernismo, anarquismo y Fin de siglo, Anthropos, Barcelona, 1990, pp.155-190.

9 Rafael Altamira y Crevea, Psicología del pueblo español, Biblioteca Nueva, Madrid, 1997, p.61

10 Nerea Aresti, "A la nación por la masculinidad. Una mirada de género a la crisis del 98", en Mary Nash, Feminidades y masculinidades, Alianza Editorial, Madrid, 2014, p. 47. 
cual le permitía superar la influencia materna por partida doble: como hijo, que se convierte en hombre y como rey, que rompe con la dependencia política respecto a la ex regente. De ahí el impacto que alcanzó el evento en la sociedad española de 1906.

El tema que propongo en este artículo es un primer acercamiento a los parámetros que componen la masculinidad y la feminidad desde la monarquía, a partir de tres ejes: los cambios y las permanencias en los fundamentos de legitimidad monárquica centrados en la figura del rey, la contribución de la narrativa matrimonial a la misma y el análisis de los elementos utilizados en la construcción del perfil público de sus representantes. El matrimonio de Alfonso XIII centra especialmente mi atención, aunque son continuas las referencias a reinados anteriores. Soy consciente de que este trabajo no aborda todos los aspectos que integran dicha construcción, ya que desbordaría el marco de un artículo. Por ello creo que es necesario profundizar en el encuadre de las figuras regias en unos estereotipos de género, construidos en términos de complementariedad desigual. Se trata de una clave interpretativa sumamente esclarecedora en torno a la compleja naturaleza del poder monárquico contemporáneo, siempre oscilante entre un aparente acercamiento a los valores de progreso y un sentido del poder más conservador.

\section{TRANSFORMACIONES EN LOS FUNDAMENTOS LEGITIMADORES DE LA MONARQUÍA}

Tras las revoluciones liberal-burguesas la dimensión jurídico-divina de la monarquía, cuyo origen fue construir una legitimidad fuerte frente a la atomización que representaba el régimen señorial, transformó el poder regio otorgando mayor peso al ámbito de la representación, aunque siguió perdurando una concepción jurídica y estatizada de la institución, fundamentada en estrategias de poder con un aparente único sentido: de arriba abajo. En realidad el rey parecía "mandar", situándose como un árbitro por encima de todas las facciones políticas ${ }^{11}$, pero la progresiva incorporación de su imagen como individuo virtuoso y ejemplar en el engranaje legitimador ponía al descubierto la verdadera naturaleza de ese poder que dependía de la nación liberal, en contraste con el poder independiente, pero arbitrario, que representaban las monarquías absolutas. Por tanto el análisis de la percepción y el impacto social de esa imagen también precisa un enfoque en sentido opuesto: de abajo arriba. En este proceso mengua el ejercicio de la potestad política, pero se amplia la visibilidad del rey, de manera que la autoridad para imponer pautas o formas de interpretar la realidad ya no es algo intrínseco a la institución, sino que depende de la capacidad de quienes la encarnan para proyectar una sensación de supremacía nacional y de poder $^{12}$. La atención recae ahora en el individuo por encima de la institución que representa, como agente único, poseedor de unos atributos especiales, cuya legitimidad ya no deriva exclusivamente de la continuidad dinástica. La parte

11 Walter Bagehot, La Constitución inglesa, Madrid, Centro de Estudios Políticos y Constitucionales, 2010 , p. 56

12 Michel, Foucault, Un diálogo sobre el poder y otras conversaciones, Alianza, Madrid, 2012, pp. 11-31. Tb. "Las redes del poder", Barbarie, 4-5, (1981-82), pp. 23-29 
eterna o divina del rey medieval deja paso a una más humana y limitada por el tiempo, que encarna el monarca contemporáneo como ideal de ciudadano. Una especie de superhombre para consumo popular en el marco de un proceso de construcción de la identidad nacional, que según Radcliff, debe "hacerse y rehacerse continuamente". Las monarquías occidentales se convierten de esta forma en agentes activos en la incorporación de "una ciudadanía en expansión a las estructuras politicas" y nacionales. La corona y el monarca devienen pilares de la construcción identitaria que ha de ser imaginada, narrada e interiorizada por la población de forma "coherente y poderosa"13, atribuyéndole un principio esencialista capaz de proporcionar un carácter natural e inevitable a la narrativa nacional.

La imagen del rey-hombre persigue responder a las expectativas de la ciudadanía. Necesita proyectar muchas facetas para convertirse en la verdadera encarnación del pueblo y construir en torno a ella un discurso homogéneo de la realeza. Las clases altas y medias constituyen su destinatario, pero en la medida en que estas actúan como emisoras de unos valores sociales prevalentes, también las clases inferiores pueden identificarse con el mismo. Por tanto, el reconocimiento, la legitimación e incluso la negación de la monarquía dependerán en gran medida de la capacidad del individuo para articular una representación flexible, pero a la vez coherente, teniendo en cuenta que no se trata del "mero producto de un mecanismo político formal, sino de cómo se produce, reproducen y se hacen circular las imágenes y las ideas"14. En este marco los signos visibles de poder se convierten en indicadores seguros de una realidad que no tiene por qué serlo y la representación en un instrumento de coacción interiorizada ${ }^{15}$.

Esta perspectiva de análisis fija su atención en la sintaxis del poder, no tanto en cómo se ejerce desde la coerción o el principio de dominación ${ }^{16}$, sino en la construcción de una legitimidad de la persuasión a partir de nuevos resortes legitimadores. Su éxito depende de que existan disposiciones permanentes, incrustadas, arraigadas en la sociedad, sin las cuales no tienen ningún efecto las estrategias discursivas o las imágenes que pretende componer una determinada fuerza simbólica ${ }^{17}$. La inmutabilidad de las monarquías ya habia sido inventada y puesta en práctica a lo largo de los siglos. Al "alto grado de fijeza y permanencia"18 que representa el rey, impreso en el imaginario colectivo, se añaden a lo largo del siglo XIX los valores de la modernidad para erradicar precisamente la idea de institución obsoleta y estática. Pero esa incorporación

13Pamela Radcliff, "La representación de la nación. El conflicto en torno a la identidad nacional y las prácticas simbólicas en la Segunda República”, en Rafael Cruz y Manuel Pérez Ledesma (eds.), Cultura y movilización en la España Contemporánea, Alianza Universidad, Madrid, 1997, pp. 306-308

14 John Street, Politica y cultura popular, Alianza Editorial, Madrid, 2000, p.61

15 Roger, Chartier, El mundo como representación. Historia cultural: entre práctica y representación, Gedisa, Barcelona, 1995, p.59

16 Steven Lukes, El poder. Un enfoque radical, Siglo XXI, Madrid, 2007, pp. 134-135

17 Fernando Molina Aparicio, "La nación, desde abajo. Nacionalización, individuo e identidad nacional”, en La nacionalización en España. Ayer, 90, (2013), pp. 39-63

18 Manuel Pérez Ledesma: "La construcción de las identidades sociales", en Justo Beramendi y Maria Jesús Baz (eds.), Identidades y memoria Imaginada, Universitat de València, València, 2008, p.23 
trae también la inconsistencia, inherente al reto de proyectar hábitos y prácticas diferentes a las tradicionales. La utilización de nuevas fuentes de sentido en la narrativa monárquica puede contribuir al derrumbe de "los esquemas clasificatorios y las estructuras que se encuentran en la base de las representaciones de los grupos" y por tanto constituyen un aspecto clave de movilización o desmovilización social ${ }^{19}$. Si las garantías de permanencia del rey no son ya exclusivamente naturales se requiere un gran esfuerzo legitimador dirigido a la pluralidad pero cuyo objetivo es la unidad. Se trata como diría Habermas de "poder dar forma y servir de soporte a una identidad colectiva" y de proporcionar "un sentido cortado al talle del propio colectivo" capaz de "suministrar perspectivas de futuro orientadoras de la acción y cubrir la necesidad de afirmación y de autoafirmación”20.

Así pues, la imagen del rey y su visibilidad son aspectos cruciales en la construcción de poder regio. El teatro Monárquico, un tratado político de finales del siglo XVII, ya habla de la necesidad de conciliar "las viejas tradiciones universales con el pragmatismo necesario para la supervivencia de la Monarquía". La fama del monarca es el núcleo del que "dimana la majestad, el poder y todo lo que debe ser así ornato de la soberanía como seguridad de la república"21. Estas recomendaciones se inscriben en un contexto históricopolitico en el que no se cuestionan las viejas esencias legitimadoras de la monarquía hispánica. Sin embargo, en las sociedades liberales la supervivencia de la institución estará sujeta a un doble fundamento: el rey representa un referente neutro cuyo objetivo es que todos los poderes "se apoyen, se entiendan y actúen de consuno"22; pero a la vez su aspiración a perpetuarse depende de "la aceptación de ficciones" que requieren la suspensión voluntaria de la incredulidad para que de alguna manera "nos creamos que el emperador está vestido aunque podamos ver que no lo está" 23 .

En este sentido Weber señala que las fuentes de legitimidad se diversifican. A la derivada del poder tradicional (historia) y del ámbito legal-racional se une aquella que procede del poder carismático ${ }^{24}$. Esto supone para las monarquías sumar a las "racionalizaciones necesarias para sostenerlas" 25 nuevos elementos ligados al campo de la representación que permitan su consolidación. Lo "legítimo" se convierte así en una "cualidad esquiva" que depende de la

19 Pierre Bourdieu, La Distinción: Criterios y bases sociales del gusto, Taurus, Madrid, 1988, pp. 241, 246, 492-494; ID., "Social Space and Simbolic Power” Sociological Theory, 7 (1989), pp. 14-22

20 Jürgen Habermas, Identidades nacionales y postnacionales, Tecnos, Madrid, 1989, p.91

21 Pedro Portocarrero y Guzmán, Teatro Monárquico de España. Edición, estudio preliminar y notas de Carmen Sanz Ayán, Boletín Oficial del Estado, Centro de Estudios políticos y constitucionales, Madrid, 1998, pp. XVII y 190

22 Benjamin Constant, Cours de politique constitutionnelle, $3^{\mathrm{a}}$ ed., Bruxelles 1837, p. 2.

23 Edmund S. Morgan, La invención del pueblo. El surgimiento de la soberanía popular en Inglaterra y Estados Unidos, Siglo XXI, Buenos Aires, 2006, pp. 13-17

24 Max Weber, Economía y sociedad. Esbozo de sociología comprensiva, Fondo de Cultura Económica, México, 1969

25 Edmund S. Morgan, La invención del pueblo. El surgimiento de la soberania popular en Inglaterra y Estados Unidos, op.cit., pp. 13-17 
capacidad del monarca para "mantener la creencia de que las soluciones politicas vigentes son las más apropiadas para la sociedad"26.

La proximidad regia es un elemento primordial en la nueva legitimidad. Los viajes reales son un ejemplo significativo del esfuerzo por popularizar una institución cuyo objetivo es ser considerada el primer referente nacionalizador ${ }^{27}$. En ellos el monarca se convierte en "interfaz viva y visible de la cual las masas pueden apropiarse de un modo casi físico"28. Las visitas a instituciones caritativas, inauguraciones, condolencias, forman parte de una ilusión forjada en torno a la capacidad del monarca para ofrecer una atención particularizada a cada situación. La ficción monárquica adquiere así pleno sentido y culmina con la presentación al mundo de la particularidad como objeto de generalidad. El reconocimiento del pueblo en su rey permite cimentar una idea abstracta e inalterable de nación a partir de identidades primarias ${ }^{29}$. Los propios monarcas y su entorno son conscientes del valor de la popularidad como agente legitimador. Amadeo de Saboya habla de un "barómetro" que mide el "amor de los pueblos", verdadero "sostén de las monarquías" 30 , mientras que Alfonso XIII señala que los reyes ya no reinan por el peso de la tradición, sino por sus actuaciones y el eco social derivado31. Por ello la prensa monárquica aplaude a un rey que posee "el don supremo de excitar el entusiasmo popular" y que es capaz de mirar "a las personas una por una (...) no dirige miradas vagas a los grupos. Los ojos buscan al individuo para sonreírle"32.

Este imperativo empático obliga a mantener en perfecto estado de revista el campo de la imagen y especialmente el de una supuesta privacidad convertida en ficción. La exposición pública de la vida privada de personajes relevantes no es nueva pero cambia su sentido. Por ejemplo, durante el periodo jacobino se convirtió en un signo de pureza ante la oscuridad, las camarillas, los subterfugios, las intrigas, la concupiscencia o los vicios inveterados de la corte. Pero con el tiempo, el "ojo revolucionario" y vigilante de un espacio público que se deseaba "panópticamente transparente" 33 se conformaría con la construcción de una realidad ficticia para consumo popular, en un contexto en el que "la vida de

26 Morgan C. Hall, Alfonso XIII y el ocaso de la monarquía liberal 1902-1923, Alianza, Madrid, 2005, p.30

27 Javier Moreno Luzón, “¿El rey de todos los españoles? Monarquía y nación”, en Javier Moreno Luzón y Xosé M. Núñez Seixas (eds.) Ser españoles. Imaginarios nacionalistas en el siglo $X X$. RBA, Barcelona, 2013, p139

28 Pierre Rosanvallon, La legitimidad democrática. Imparcialidad, reflexividad y proximidad, Paidós, Madrid, p. 261-262 21

29 Craig Calhoun (edit.), Social Theory and the politics of identity, Blacwell, Oxford, 1995, pp.20-

30 Antonio Pirala, El rey en Madrid y en provincias, Quirós impresor de cámara, Madrid, 1870

pp. 3-5; Carta de Amadeo I a su padre, Archivo General de Palacio, Reinados, Caja 16/12, carta II (s.f.)

${ }^{31}$ Carta de Alfonso XIII a Manuel de Portugal, 10 de septiembre de 1908, Archivo General de Palacio, Registros, libro 698

32 Diario de las Palmas, 25 de Enero de 1925

33 Ramón Maíz, "Las teorías de la democracia en la Revolución francesa", en Política y sociedad 6/7 (1990), pp. 66 y73. Michel FOUCAULT, "El ojo del poder", en Jeremy Bentham, El Panóptico, La Piqueta, Barcelona, 1979. pp. 16-17 
los reyes fue escrutada por un público creciente"34. La banalidad regia se compone así de pequeños retazos que configuran el collage perfecto de la vida privada de los reyes que guarda "cierto grado de simetria entre la realidad objetiva y la subjetiva" 35 . Se trata de una perfecta réplica de la vida familiar reconocible por la ciudadanía, capaz de encajar en las expectativas colectivas y en la que se exaltan valores como la sencillez, el amor, el trabajo, para evocar cercanía y humanidad. Sarah Maza señala en este sentido que la imagen de familia y la domesticidad empieza a gestarse ya en el siglo XVIII. Introduce la idea de una realeza que asume la escenificación del imaginario familiar burgués, encarnado perfectamente por Luis Felipe de Orleans y su esposa. Este ajuste de la institución al campo de las representaciones del Tercer Estado ${ }^{36}$ persigue salvar el oximoron inherente a la pervivencia de la monarquía posrevolucionaria y atraer un interés creciente de la ciudadanía por sus más altos representantes. Así por ejemplo, unos "deliciosos párrafos consagrados al hombre-rey", para describir la sencillez en los gustos gastronómicos de Alfonso XII, se convierten en objeto de especial atención, teniendo en cuenta que "a todos nos encanta el relato de esas menudencias cuando se refieren a los príncipes o a los hombres célebres". 37

La figura de Amadeo de Saboya encajaba perfectamente en una concepción de la soberanía fundamentada en el rechazo de los privilegios y en la cercanía. Era un "raro caso de monarca electivo que debía ganarse el favor popular"38 para conseguir la consolidación dinástica. Sin embrago por lo general, la monarquía española contemporánea combinó los grandes ceremoniales que materializaban la excepcionalidad de la institución con actos menos "majestuosos" destinados a proyectar la idea de proximidad. No solo Amadeo era el "rey de los pobres, el rey caballero" 39 , con su particular saludo en los desfiles ${ }^{40}$. También Alfonso XIII se mostraba como le roi charmant ${ }^{4}$, activo $\mathrm{y}$ jovial que en el marco del regeneracionismo finisecular buscaba encarnar la definitiva transformación de la nación ${ }^{42}$.

34 Javier Moreno luzón, “¿El rey de todos los españoles? Monarquía y nación”, en Javier Moreno Luzón y Xosé M. Núñez Seixas (eds.), Ser españoles. Imaginarios nacionalistas en el siglo $X X$, RBA, Barcelona, 2013, p. 151

35 Peter Berger y Thomas Lucmann: La construcción social de la realidad, Madrid, Amorrortu, 1986, pp. 182-185. También Jaap Van Osta: “The Emperor's New Clothes. The Reapearance of the Performing Monarchy in Europe, c. 1870-1914", en Jeroen Deploige and Gita Deneckere. Mystifying the Monarch: studies on discourse, power, and history. Amsterdam University Press, Amsterdam, 2006, pp. 182-183.

36 Sarah Maza, The Myth of the Franch bourgeoisie. An Essay on the Social Imaginary 17501850, Harward Universtity press, Cambridge (Massachusetts), 2003, pp. 61-62 y 191

37 La Mlustración española y americana, 30 de enero de 1878

38 Gil Blas, 5 de enero de 1871

39 Real Biblioteca, José María Huici: Al rey de España Amadeo I, Historia 29-6 (60)

40 José Berruezo, La España del Rey Amadeo. Conferencia pronunciada en el Instituto Italiano de Cultura de San Sebastián, 1943, p. 21

41 Javier Moreno Luzón, "El rey de papel” en Javier Moreno Luzón (edit.), Alfonso XIII. Un politico en el trono, Marcial Pons, Madrid, 2003, p. 37

42 Claude Rivière, Liturgie politiche, Edicione di red studio redazionale, Como, 1998, p. 13 
Con el rey Amadeo I el impulso modernizador cobró un gran protagonismo como eje legitimador. En una España "regenerada" tras la revolución, él representaba esa clase de reyes que "saltando por encima de rancias costumbres, saben y quieren conocer los medios de engrandecer a los pueblos" para situar a "nuestra querida patria" al "frente de la civilización del mundo" 43 . También con su sucesor, Alfonso XII, llegarian "todas las grandes ideas" e "iniciativas generosas" al país, en "el orden material y en el orden moral". ${ }^{44}$ Aunque el dinamismo y la aparente plasticidad de la imagen regia alcanzaron su máxima intensidad con Alfonso XIII y sus facetas como rey soldado, viajero, afable, cercano, preocupado por su pueblo o impulsor de la industria y el progreso, "que presta su valiosísimo apoyo a toda idea nueva que suponga un adelanto"45. Según Morgan la representación pública de la realeza alfonsina estaba destinada a "contrarrestaro al menos legitimar- la imagen del rey como actor politico". El compromiso de la monarquía con el ideal de regeneración aplicado a "los políticos, las políticas y las instituciones" del momento ${ }^{46}$, le obligaba a presentar una imagen completa, sin resquicios para la duda respecto al alcance de dicho compromiso.

Pero la escenificación de la realeza no podía renunciar del todo a la majestad. La monarquía inglesa, y especialmente la reina Victoria, es el paradigma en este sentido. Proyectaba una imagen de continuismo y apego a la tradición que actuaba a modo de anclaje estabilizador ante las dificultades y profundas transformaciones de su tiempo para generar la sensación de seguridad y permanencia ${ }^{47}$. En España los rituales, no alcanzaron ese grado de solemnidad y pompa, aunque también perseguían el mismo objetivo. Entre ellos, la ceremonia de la comida y el lavatorio de pies, celebrada desde el siglo XIII en España era una de las más representativas de la Semana Santa ${ }^{48}$. La escena del rey y de la reina, que a imitación de Jesucristo lavan los pies a veinticinco hombres y mujeres contribuia a sublimar la institución que encarnaban a través de la caridad. Así, el jueves santo de 1878 el rey Alfonso XII "se quitó los guantes y la espada", mientras que la reina "que vestía de "tisú de oro con manto de terciopelo morado," cogía la toalla que le ofrecía la Marquesa de Santa Cruz en una bandeja de oro. Tanto lujo quedaba contrarrestado con la actitud de la reina Mercedes, quien, "muy emocionada, secaba los pies y los besaba con toda humildad"49. En el caso de Alfonso XIII y su esposa, Victoria de Battemberg, el ceremonial estaba absolutamente pautado y también muestra toda la pompa de

43 Real Biblioteca Manuscritos/790 Industriales de Sabadell a S.M. el rey D. Amadeo I.

${ }^{44}$ La Ilustración española y americana 30 de noviembre de 1885.

45 Archivo General de Palacio, Reinados, Alfonso XIII, Caja 12413. Notas procedentes de la Secretaría Particular de S.M. el Rey (Conmemoración bodas de plata del reinado)

46 Morgan C. Hall, "El rey imaginado", en Javier Moreno Luzón (ed.) Alfonso XIII. Un politico en el trono, op. cit. pp. 62-64

47 David Cannadine, "Contexto, representación y significado del ritual: La monarquía británica y la "invención de la tradición" 1820- 1977, en Eric Hobsbawm. y Terence Ranger (eds.) La invención de la tradición, Crítica, Barcelona, 2002, p.151

48 Pedro Carlos González Cuevas, "El rey y la Corte", en Javier Moreno Luzón (edit.) Alfonso XIII. Un politico en el trono, Madrid, op.cit, pp. 203- 204; ÍD.: “Alfonso el Regenerador. Monarquía escénica e imaginario nacionalista, en perspectiva comparada (1902-1913), en Hispania, Vol. 73, 244, (2013), p. 327

49 Ana de Sagrera, La reina Mercedes, Compañia Literaria, Madrid, 1995, p. 361 
la Corte. Asistía la familia real, ministros y numerosos miembros del cuerpo diplomático, cuyos familiares expresaban "su mayor empeño" por presenciarla, como si se tratara de un espectáculo exótico. Nada se dejaba al azar, desde el atuendo, "uniforme de gala y calzón corto", el número de asistentes, "señores, gentileshombres y grandes de España", así como los ocupantes del lado del evangelio o el de la epístola para presenciar cómo los reyes servian a trece hombres y doce mujeres pobres que resultaron agraciados por sorteo, tras su correspondiente limpieza y examen médico ${ }^{50}$. El diario $A B C$ describe la ceremonia e incide en la distribución de roles en la pareja real:

"Al comenzar la ceremonia del lavatorio desaparecen ante nuestros ojos los esplendores de la Corte, para contemplar al Rey inteligente, valeroso y admirado en toda Europa, postrado ante los pobres, cuyos pies lava y besa (...) y la Reina, llena de juventud y hermosura lava a su vez los pies de doce mujeres pobres (...) Todas las grandezas de la tierra encarnadas en nuestros monarcas, de rodillas, ante los pobres..."51

\section{EL MATRIMONIO REAL EN LA NARRATIVA LEGITIMADORA}

La proyección de toda imagen desde el poder y su éxito en el campo de las percepciones conlleva un "pacto ficcional" por el cual en mayor o menor medida se suspenden los juicios de verdad ${ }^{52}$. En este sentido el matrimonio regio constituye un excelente marco para la exposición pública; una estrategia destinada a dotar de coherencia a la monarquía. Su narrativa, especialmente la que rodea la boda y los nacimientos, recurre a la pompa y al esplendor inherente a la institución pero también se alimenta de elementos inscritos en el imaginario popular para desencadenar un efecto de proximidad ${ }^{53}$. El matrimonio de los reyes en las monarquías absolutas fue determinante para resolver muchos conflictos de Estado $^{54}$, pero en las contemporáneas se convierte en un elemento de racionalidad estratégica ya que contribuye a diluir la naturaleza paradójica de la institución, otorgándole un sentido de verdad. En la búsqueda de nuevos elementos de cohesión nacional, estas uniones, y especialmente la imagen de la reina consorte, aportan un nuevo significado a la monarquía, al compás del progresivo protagonismo que adquiere en la opinión pública la ficción doméstica y la banalización regia.

A lo largo del siglo XIX el relato matrimonial de la corona conjuga los aspectos más atávicos con los nuevos valores asociados a la modernidad. Así por

50 Archivo General de Palacio, Reinados, Caja 8777-3 Exp. 1910-1914.

51 ABC, 2 de abril de 1920

52 Umberto Eco utiliza este concepto literario que acuñó el poeta y filósofo inglés Samuel Coleridge en el siglo XIX, en Seis paseos por los bosques narrativos, Barcelona, Editorial Lumen, 1996.

53 Bernd Weisbrod, “Theatrical Monarchy: The Making of Victoria, the Modern Family Queen”, en Regina Schulte (ed.), The body of the queen. Gender and rule in the courtly world, Berhahn books, New York, 2006, pp. 246-247

54 Joaquín Tomás Villarroy, "Sucesión a la Corona" en Oscar Alzaga Villaamil, Comentarios a las Leyes Politicas. Constitución española de 1978, EDERSA, Madrid, 1983-1989.T. V, pp. 77-173 
ejemplo los diputados describen a la nueva reina $\mathrm{M}^{\mathrm{a}}$ de las Mercedes como "española y católica, descendiente de cien reyes y dotada de las más altas prendas", el fundamento perfecto de "la vida doméstica del rey"55. De la misma forma, en la boda de Victoria de Battenberg con Alfonso XIII se resaltó el linaje de la novia, nieta de la reina Victoria, "maestra de libertades y cosechadora de grandezas", junto a expresiones patrióticas relacionadas con las viejas aspiraciones españolas sobre Gibraltar o al incremento de la influencia en Marruecos. Pero la joven reina también simboliza la regeneración política relacionada con el prestigio del modelo institucional inglés, considerado una "inspiración" para la política española56, que así conseguiría conectar "nuestra ordinaria comunicación espiritual con el universo culto"57. Aunque existían otras interpretaciones del enlace que lo consideraban como un primer paso para que Inglaterra pudiera "indostanizar a España"58 o como instrumento de propaganda calificado de "cuento de las mil y pico noches"59 por los republicanos.

Los periódicos monárquicos ensalzaron las ventajas de esta boda desde muchas perspectivas. Por ejemplo, la vincularon con la buena marcha económica del país ya que muchas parejas decidieron casarse el mismo día. También resaltaron el hecho de que "manos de obreras españolas"60 hubieran confeccionado el traje de novia y de que algunas joyerías y perfumerias aprovecharan el tirón del enlace anunciando el "Perfume de los Reyes de España por 7 pesetas" 61 . En esta composición matrimonial destacan especialmente los comentarios que rechazaban las uniones fundamentadas puramente en la obediencia y en el respeto como valores ligados a la aristocracia tradicional ${ }^{62}$, a pesar de que en la España de estos años no existian "unos patrones tan definidos a la hora de hablar de la nobleza", que en muchos sentidos era un referente a seguir63. La imagen de la boda por amor se presentaba como una nueva tendencia que había llegado hasta la monarquía, no solo como un signo de modernización de la institución sino de su capacidad para identificarse con el pueblo. Ya Alfonso XII prefirió casarse por amor "como se casan los pobres"64 y su hijo demostraba igualmente que "el amor es tan igualitario, que lo mismo es el

55 Felicitaciones de los diputados a la futura reina en el Palacio de Aranjuez el 20 de enero de 1878. La Ilustración española y americana, 30 de enero de 1878.

56 Sesión de las Cortes del 13 y 14 de marzo de 1906. El Imparcial, 7 de junio de 1906

57 El liberal, 26 de mayo de 1906

58 Joaquin Costa escribe en El Motín, 14 de abril de 1906

59 El Motín, 2 de junio de 1906

60 El liberal, 24 y 30 de mayo de 1906. En Madrid "más de 200 bodas coinciden con la rey". Con el tiempo la publicidad a costa de la monarquía alcanzaria hasta la leche infantil. Así, "Glaxo. La nodriza del siglo XX" se anuncia como "alimento de príncipes y "proveedor de la Casa Real". Nuevo Mundo, 14 de enero de 1914

61 El Liberal, 31 de mayo de 1906

62 Jo Burr Margadant, "Les représentations de la reine Marie-Amélie dans une monarchie " bourgeoise ", en Revue d'histoire du XIX siècle, 36, (2008/1), p.94

63 José Miguel Hérnández Barral, “Ser noble en la España de Alfonso XIII”, en Cuadernos de Historia Contemporánea", 32, (2010), p. 194

64 Se refiere a la boda de Alfonso XII con Mercedes de Orleans. La Ilustración española y americana, 30 de enero de 1878 
rey que el cadete enamorado"65. En un artículo titulado "El rey y la prensa" Alfonso XIII presentaba a su prometida a los periodistas. Era una oportunidad excelente para mostrarse como "un hombre de su tiempo", "abrumado por los mil detalles de una suntuosa ceremonia", capaz incluso de contemporizar con periodistas republicanos sin "velos y coberteras de fórmulas ritualistas" 66.

En una de las muchas referencias al futuro matrimonio se compara el "Antiguo y moderno régimen" y se justifica que Felipe IV tuviera tantos hijos naturales porque no se casó enamorado, a diferencia del joven Alfonso, que "ha bajado del trono para ser novio feliz". Junto a su pareja era como cualquier hombre cuya juventud y virilidad le hacian ser "ardiente, pasional". Pero a pesar del "incendio de sus miradas", Victoria se muestra siempre tímida y recatada, mientras que el rey expresa "el ciego y devotísimo amor" de un soldado67. En algunos escritos el amor de los recién casados trasciende los sentimientos y se convierte en simbolo de los nuevos tiempos, visible hasta en el viaje de novios, en "tren expreso / con las almas y las manos enlazadas / que son siempre en el mundo respetadas las leyes de la moda y del progreso"68.

Esta boda constituyó un campo idóneo para la escenificación de los nuevos valores de la monarquía. De un lado, el puro entretenimiento y la curiosidad popular, claro sintoma de la cercanía regia, evidente en el deseo de intimidad expresado (públicamente) por la pareja al ser objeto de una excesiva atención por parte de la prensa y el público ${ }^{69}$. El evento se convirtió en un motivo para la evasión pues "todos, dejando atrás la vulgar monotonía de políticas y convencionalismos se olvidan de los problemas". De otro, su consideración como representación viva de la esperada regeneración nacional, ya que "al ver pasar la real pareja la idea absoluta de realeza desaparece ante la idea relativa de una sangre moza" porque nadie "piensa que esas dos almas son el símbolo de una realeza deslumbrante" y "solo olvidando el pasado nos iremos regenerando y saliendo de las tinieblas de la oscuridad"70. Esta unión constituía un "toque de recogida para que los cadáveres y las momias se encierren definitivamente en sus sepulturas" y por consiguiente el principio de "una nueva estación" en la que "las hojas mustias y las ramas secas tendrán que ceder a brotes y retoños jóvenes el sitio al que todavía permanecen aferradas"71. Incluso los indultos fueron valorados precisamente como uno de los primeros síntomas del cambio ${ }^{72}$.

La juventud y el amor ponian de relieve la afinidad del pueblo con su rey en el marco de un acontecimiento "eminentemente popular" frente a ceremonias anteriores, consideradas como "eventos puramente cortesanos". Las gentes

65 El liberal, 28 de mayo de 1906

${ }^{66}$ El Imparcial, 31 de mayo de 1906

67 Nuevo Mundo, 26 de mayo de 1906

68 Gabriel Enciso Núñez, A.S.M. El rey Don Alfonso XIII con motivo de su enlace con S.M. la reina Doña Victoria, Madrid, 1906

69 El liberal, 27 de mayo de 1906; El Imparcial publicó durante todo el mes de mayo una especie de crónica sobre las actividades que desarrollaban los novios bajo el título "La princesa y el rey"

70 La Publicidad, 29 de mayo de 1906

${ }^{71}$ El Liberal, 30 de mayo de 1906

72 El liberal, 30 de mayo de 1906 
sencillas veían a los reyes como un ejemplo a imitar, "eh ahí porque las bodas de hoy son algo más que un matrimonio de príncipes y tienen una honda base popular"73. Por eso el triunfo "amor" está por encima de la "razón de Estado" y otorga "a los reyes popularidad, prestigio a los tronos y solidez a las coronas"74. Aunque era inevitable que en este tipo de acontecimientos convivieran "la majestad" y el "trivialismo"75.

Las relaciones de género en una colectividad forman parte del proceso de construcción identitaria de la misma ${ }^{76}$. En el hogar familiar hombres y mujeres desarrollan una dinámica propia, que convertida en modelo, se proyecta como escaparate de la esencia nacional. En la monarquía esta idea adquiere pleno sentido pues una vez celebrada la ceremonia nupcial, la familia real constituye una fuerza de atracción y de irradiación de valores, acorde con "la gran mitificación burguesa de la domesticidad" que ocupa "un lugar central entre los mecanismos de legitimación, pero también de apropiación por parte de los ciudadanos, de las monarquias constitucionales"77. De manera que la estructura familiar en la monarquía se convierte en una forma de categorización social. Segismundo Moret se refiere al matrimonio de Alfonso XIII como la "primera familia del reino, el hogar con el que estamos identificados", si "allí no reinase la felicidad, la virtud, la tranquilidad, no podría exteriorizarse todo aquello que signifique el buen gobierno del país"78.

En ocasiones, la exposición pública de la familia real estaba sujeta a los vaivenes sociopolíticos. Así, la asistencia al "ballet" de sus miembros "con sus mejores atavios" buscaba disipar, "siquiera por una noche, preocupaciones políticas" y ofrecer una imagen de entusiasmo popular ante la realeza, en un clima de grave inestabilidad social, como fue el verano de $1917^{79}$. El propio rey, utilizaba la imagen del amor y la familia para fundamentar el papel de la monarquía en la unión entre los españoles, visibles desde el matrimonio entre Isabel y Fernando ${ }^{80}$.

Pero en un cuadro de armonía familiar es necesario definir muy bien los papeles de los protagonistas, para mostrar el lado humano y sobrehumano del rey junto a una esposa ejemplar, cuya figura adquiere "todo su sentido y

73 El liberal, 31 de mayo de 1906

74 La correspondencia de España 25 y 26 de mayo de 1906.

75 Arturo Mori, Alfonso XIII 1886-1941. Vida Emotiva y genuinamente española de un rey tipico, ed. Mexicana, México, 1943, p.99

76 Nira Yuval-Davis, "Nationalist Projects and gender relations", Nar.umjet. 40/1, (2013), pp. 16-17

77 Isabel Burdiel, "Edición y estudio introductorio" en SEM, Los Borbones en pelota, Institución "Fernando el Católico", op.cit. p. 26.

78 Diario Oficial de las Sesiones de Cortes. Proyecto de contestación a la comunicación del gobierno, participando el propósito de S.M el rey de contraer matrimonio con su S.A.R. la princesa Victoria Eugenia de Battemberg. Archivo General de Palacio, Reinados, Alfonso XIII, 12.911/24

79 Arturo Mori se refiere a la huelga revolucionaria de 1917, en Alfonso XIII 1886-1941. Vida Emotiva y genuinamente española de un rey tipico, op.cit. p. 197

80 Discurso del rey ante los alcaldes catalanes en la Mancomunidad del 19 de mayo de 1924. José Gutiérrez-Ravé, Habla el Rey. Discursos de Don Alfonso XIII, Madrid, 1955, pp-262-263 
significado" derivado del matrimonio ${ }^{81}$. La composición de estereotipos de feminidad y masculinidad en este marco debe responder a diversas expectativas colectivas de su tiempo, con el fin de que la monarquía y su identificación con la nación no sean cuestionadas. Es por tanto una vía de doble sentido en la que las figuras regias proyectan imágenes y modelos de comportamiento sobre la sociedad que a su vez los genera. Solo si los monarcas contemporáneos se ajustan a esta dinámica, sin renunciar a los principios tradicionales de la institución, pueden convertirse en catalizadores de la esencia nacional. A pesar de su aparente inmovilidad se trata de construcciones en formación, complejas y llenas de matices.

\subsection{Alfonso XIII: Una masculinidad en construcción}

El enfoque de la figura del rey-hombre en ocasiones aparece borroso pese a que representa a una institución masculina, caracterizada por la fortaleza, valentía o virilidad, como referentes de identificación nacional. A lo largo del siglo XIX la frontera entre unos parámetros de masculinidad burguesa y otros relacionados con los viejos códigos de honor, procedentes del antiguo régimen, no está perfectamente delimitada. En realidad se observa una resistencia de estos últimos a desaparecer ya que la burguesía, supuestamente vinculada al talento como criterio jerárquico, se siente al mismo tiempo atraída por el prestigio de la vieja aristocracia, ligado a valores de superioridad, exclusividad o distinción ${ }^{82}$.

La monarquía posee su propia dinámica aristocrática destinada a despertar respeto y admiración. Así, Alfonso XIII es calificado en una de sus biografias como "El caballero de España", ejemplo de la más rancia esencia hispana83, a la que sin embargo debe unir, si quiere construir un discurso de "masculinidad hegemónica", las nuevas prácticas de sociabilidad burguesa que le permitirán convertirse en "ideal normativo" en torno a todas las "formas de ser hombre" 84 . Morgan Hall, señala en este sentido que Alfonso XIII ofreció diversas imágenes que se ajustaban a los intereses de cada momento. Desde las oficiales, entre las que destaca el rey soldado, deportista, hombre de Estado, hijo amantísimo, devoto padre de familia, apuesto gentleman moderno, a las extraoficiales, como el niño mimado, enfermo, mujeriego o el dandy ${ }^{85}$. En un intento por abarcar todos los discursos no hubo continuidad en la política de imagen del rey, lo cual impidió la construcción de una narrativa nacional unificada y contribuyó a una fragmentación de la sociedad y a la debilidad del sentimiento nacional español.

${ }^{81} \mathrm{M}^{\mathrm{a}}$ de lo s Ángeles Pérez Samper, "La figura de la reina en la monarquía española de la edad moderna", en $\mathrm{M}^{\mathrm{a}}$ Victoria López-Cordón y Gloria Franco (coords.), La reina Isabel y las reinas de España: realidad, modelos e imagen historiográfica, Fundación Española de Historia Moderna, Madrid,2005, p. 293

82 Robert A. Nye, Masculinity and male codes of honor in modern France, Oxford University press, London, 1993, pp.8-9.

83 Vid. Julián Cortés Cavanillas: Alfonso XIII. El caballero de España, Ediciones Nuestra Raza, Madrid, 1848.

${ }^{84}$ Nerea Aresti, Masculinidades en tela de juicio, Cátedra, Madrid, 2010, p. 17

85 Morgan Hall, p. 61y 81-82 Morgan C. Hall, Alfonso XIII y el ocaso de la monarquía liberal 1902-1923, op.cit. p. 61y 81-82 
Nagel indica que la construcción de la masculinidad moderna es paralela al desarrollo del nacionalismo al quedar identificados el patriotismo, la valentía y el deber como atributos masculinos ${ }^{86}$.Como afirma Aresti, durante el reinado Alfonsino la categoría "hombre español" es inestable. Al igual que el ideal de masculinidad, también el concepto de nación es difuso ${ }^{87}$. Así al arquetipo regio construido a partir de la imagen del hombre moderno, cosmopolita y dinámico, capaz de superar la idea de una España abúlica, inerte y excluida de la modernidad, se opondría la figura del tradicional caballero español, vinculado a valores como el honor, la jerarquía y la respetabilidad. En realidad eran modelos de difícil pero necesaria compatibilidad en esos momentos. Para los sectores más conservadores, soporte secular de la monarquía, los referentes extranjeros suponian un alejamiento del modelo cultural tradicional, considerado la verdadera esencia de españolidad. En cambio, los partidarios de una monarquía moderna veían en el rey la encarnación del progreso del país. Junto a lo "moderno" y las viejas esencias, el monarca tampoco debía perder de vista los valores de la domesticidad victorianos ${ }^{88}$. En este sentido Martin Francis apunta que entre el siglo XIX y el XX comienza a surgir la imagen de una hombría vinculada a la domesticidad que no necesariamente renuncia al ideal de una vida heroica, lo cual constata la complejidad de los estereotipos: no existe un único modelo de "ser hombre" sino que se vislumbran varios referentes que oscilan entre pautas de masculinidad aparentemente contradictorias ${ }^{89}$.

El primer paso en la construcción del estereotipo varonil regio se detiene en aspectos puramente físicos, aunque nada superficiales, pues ya Locke y Rousseau consideraban que un "cuerpo fisicamente correcto resulta esencial para una inclinación moral adecuada". La belleza corporal es metáfora de virtud y ocupa un lugar destacado en el modelo ideal masculino ${ }^{90}$. Tanto Amadeo de Saboya, "joven, guapo y meridional"91, como Alfonso XII, "guapo mozo"92 proyectan la idea de belleza como signo de los nuevos tiempos. La figura de Alfonso XIII no se ajusta a los mismos cánones pero igualmente se utilizan aspectos de su anatomía para resaltar sus virtudes. Churchill lo definía "esbelto, ágil, optimista, su mente y su cuerpo armonizaban"93. Aunque desde el republicanismo se remarcaba la "endeblez" del rey y "la racha de augustos

86 Joane Nagel, "Masculinity and nationalism: gender and sexuality in the making of nations," en Ethnic and Racial Studies Volume 21 2, (1998), p. 243

87 Nerea Aresti, "Masculinidad y nación en la España de los años 1920 y 1930 ", Mélanges de la Casa de Velázquez, no 42/2 | (2012), p. 55.

88 John Tosh, A man's place. Masculinity and the Middle-Class Home in Victorian England, Edmundsbury Press, Bath, 2007, pp. 27-50

89 Martin Francis "A flight from commitment? Domesticy, adventure and the masculine imaginary in Britain after the Second World War, in Gender an History, 19/1, (2007), pp. 163-185

90 George L. Mosse, La imagen del hombre. La creación de la masculinidad moderna, Talasa, Madrid, 2000, pp. 34-35

91 José Berruezo, La España del Rey Amadeo. Conferencia pronunciada en el Instituto Italiano de Cultura de San Sebastián, 194, p.22

92 Juan Valera, Cartas intimas 1853-1897, Taurus, Barcelona, 1974

93 Capítulo de Grandes Contemporáneos, escrito por Wiston Churchill incluido por Julián Cortés -Cabanillas, en Alfonso XIII, vida, confesiones y muerte, Juventud, Barcelona, 1966, p. 9 
enfermos que le estaba reservada a España"94. El "prognatismo real" fue en su momento objeto de atención entre quienes querian presentar al monarca como referente de perfección. Para el "español más español que se pueda imaginar" ¿era posible poseer un "estigma de degeneración?". Esto era imposible, "un absurdo científico" propagado por "autores sin estudios". Personajes tan insignes como Cristóbal Colón fueron prognatos. Se trataba de un "achaque" que afectaba a todas las casas reales. En realidad "la raza íbera tiende a ser prognata" de manera que en el rey era un signo de majestad y de españolidad extremas, que incluso daba "cierto empaque de abolengo". Sus virtudes morales se encontraban en total consonancia con un físico tan español: el monarca era "1lano, cortés, democrático, justo, ecuánime y ponderado", sin "noción de su categoría. Despiertísimo, de una inteligencia luminosa...."95.

El resalte de la doble condición de varón y de rey es un aspecto de suma importancia en el caso de Amadeo y Alfonso XIII. Sus reinados, en contextos muy distintos, llegaron después de dos reinas, Isabel II y Maria Cristina de Habsburgo. Su entronización fue percibida como el triunfo de la masculinidad frente a la depravación de la primera y el espíritu monacal de la segunda. Amadeo era el hombre "bello", joven, fuerte, valiente, el "macho" después del largo reinado de una mujer corrupta96. Alfonso representa al rey joven y enérgico que rescatará a la nación después de "un siglo casi entero en que han sido regidos nuestros destinos por mujeres"97. Encarna a "un democrático hombre de mundo, moviéndose fácil y naturalmente en toda clase de sociedad" en contraste con "la sombría y solemne etiqueta de la Corte española" que había instaurado su madre ${ }^{98}$. En los primeros años de reinado, cualquier signo de cambio en los usos y costumbres del rey es interpretado como un indicio de regeneración nacional.

Aún más, ambos monarcas sufrieron sendos atentados que realzaron su imagen. El italiano demostró su valentía, entereza y serenidad al pasear sin escolta a pesar de las advertencias ${ }^{99}$. El atentado que sufrió Alfonso XIII el día de su boda también puso de manifiesto "su admirable serenidad" al ser capaz de dar a la reina la confianza de un protector y un guía. El rey se ajusta así al estereotipo de caballerosidad y dinamismo frente al que representan las reinas,

94 Arturo Mori, Alfonso XIII. Vida emotiva y genuinamente española de un rey típico. (Carátula y viñetas de Carmona) México, 1943, p.106

95 Juan Torrendell, Alfonso XIII, rey de España. (Notas de su vida y su reinado), Tor, Buenos Aires, 1916, pp. 104-124

96 Giovanni Ferreri: Amedeo di Savoja duca d'Aosta, già re di Spagna. Memorie storiche racolte ad uso delle scuole e delle famiglie, Torino, G. Scioldo Editore, 1890, p. 14

${ }^{97}$ Escrito firmado por Juan Español de 23 de Enero de 1905. Archivo General de Palacio, Reinados, Alfonso XIII, X/335 (10)

98 Capítulo de Grandes Contemporáneos, escrito por Wiston Churchill incluido por Julián Cortés -Cavanillas, en Alfonso XIII, vida, confesiones y muerte, op. cit. p. 11

99 Conde de Romanones: Amadeo de Saboya, el "rey efimero" Madrid, 1956, p. 30; Ana de Sagrera: Amadeo y $M^{a}$ Victoria, reyes de España. 1870-187, Palma de Mallorca, 1959, pp.257-59 
cuya feminidad calmada y pasiva100 se vincula además con su particular habilidad para conmover ${ }^{101}$.

El pueblo español ha sido bendecido por la energía de un monarca que "lucha por el bien" y sabe resignarse "ante las adversidades". Sus decisiones no son simples gestos de arrojo momentáneo porque dos días después del atentado:

\begin{abstract}
"los reyes, sin escolta, sin policía, sin miedo, avanzaban gallardamente, sonriendo, tranquilos, entregados por completo al pueblo, a la multitud clamorosa, que hubiera sido capaz de destrozar al que osara no ya cometer un atentado, sino la menor irreverencia con los monarcas. (Los reyes) en su pueblo y solamente en su pueblo, es donde buscan protección en la hora de los más grandes peligros".
\end{abstract}

Y por si fuera poco, el atentado permitió demostrar que España estaba liderada por un liberal y un demócrata convencido, que descartó una "política de represión y de fuerza" a partir de dictámenes decretados "sin empacho de legalidad". El rey optó por el "derecho y la popularidad, el prestigio y las simpatías de un dictado supremo", como la "perfecta expresión" del "modelo de monarca constitucional", que ejerce un "poder responsable" y "moderador", una "autoridad no sujeta a mudanzas"102. La imagen del rey valiente será recurrente en los discursos de Alfonso XIII que en la última etapa de su reinado se consideraba a sí mismo "un hombre como vosotros, que sabe cuáles son sus obligaciones y que en ningún momento desertará de su puesto y que no tiene absolutamente miedo a nada ${ }^{103}$.

Junto al físico, la valentía y el sentido de Estado, que ya exhibió en su momento Amadeo de Saboya, la figura del rey-hombre se proyecta en constante equilibrio entre lo sobrenatural y la normalidad más absoluta, capaz de comportarse "como un ciudadano cualquiera que no posee gran riqueza"104. La construcción de la imagen de Alfonso XIII supera esos parámetros para convertirle en el incansable patriota cuyo omnipresente dinamismo resulta patente durante la Primera Guerra Mundial y plenamente consolidado durante el posterior régimen primorriverista, en el que patria y masculinidad "aspiraban a significar una misma cosa"105. El rey, "muy español, muy sencillo, sin alardes etiqueteros en cuanto a la regla de su hogar"106 expone en "La vida que hace un

100 George L. Mosse, La imagen del hombre. La creación de la masculinidad moderna, op. cit., p. 19

101 Barbara F. Weissberger, Isabel Rules. Constructing Queenship, Wielding Power, of Minnesota Press, Mineapolis University 2003, pp. 187-188.

102 El Imparcial, 1, 5, 6 y 8 de junio de 1906

103 Discurso del rey ante los alcaldes catalanes en la Mancomunidad del 19 de mayo de 1924. José Gutiérrez-Ravé: Habla el Rey. Discursos de Don Alfonso XIII, Madrid, 1955, p. 263

104 La Paz, 10 de enero de 1871

105 Nerea Aresti, Masculinidades en tela de juicio, op. cit., p. 298

106 Julián Cortés Cavanillas, Alfonso XIII. El caballero de España, Ediciones Nuestra Raza, Madrid, 1948, p. 82 
rey" ${ }^{107}$, su supuesta privacidad, que sale a la luz por la osadía de una especie de corresponsal infiltrado. El objetivo es contrarrestar un perfil público "excesivamente superficial" en un momento de la crisis política de 1917: demasiada caza, paseos, deporte y diversión, a costa de los verdaderos problemas que afectaban a la nación. El artículo describia una estampa muy distinta. El rey siempre trabajando en un "amable rinconcito de dos habitaciones exageradamente sencillas" similares a las "de un estudiante", llenas de papeles y libros de todas las materias, economía, agricultura, industria, minería, incluso medicina. Destacan las estadísticas y los datos técnicos porque le permitian conocer "el desenvolvimiento de la riqueza nacional" y un libro abierto encima de la mesa, Le régime des prissioners de guerre ${ }^{108}$.

Un monarca inteligente pero sobre todo español, "trasnochador como buen madrileño" al que en ocasiones, por el duro trabajo, se "le pegan las sábanas como a cualquier mortal". Fumaba mucho, pero solo consumía tabaco "normalito" y en las audiencias, recibia a todo el mundo con "un trato que hace amigos". Su actividad frenética nunca le permitía comer en familia y mucho menos hacer siesta, aunque era un marido y un padre ejemplar. La luz de su despacho siempre estaba encendida porque el rey continuamente tenía "el pensamiento puesto en la patria". Es por ello que con apenas 30 años se veía obligado a usar lentes. El cronista, "sorprendido" haciendo fotos por el propio rey, transcribe sus palabras: "Que se vean bien mis dos religiones, la bandera y el crucifijo". Frente a las críticas aduce que "por dos o tres horas que dedico a higiénicos paseos y saludables ejercicios, necesarios para un hombre que hace, como yo, una vida sedentaria, se juzga toda esta" y justifica su pasión por los "sports" en la oxigenación y sus beneficiosas consecuencias que repercutian directamente en una eficaz resolución "de los problemas del país".

Pero las enormes responsabilidades regias no eran incompatibles con las continuas infidelidades y aventuras amorosas del monarca, que en realidad formaban parte del tradicional universo masculino de la monarquía y que estaban relacionadas con un estereotipo de virilidad donjuanesca, considerado por muchos como "el sello de nuestra raza y nuestro timbre de gloria, nuestra ejecutoria"109. El único requisito no escrito era que la "discreción encubriera las faltas naturales de un rey" que tenía derecho a un "legal esparcimiento". En los tres monarcas citados la infidelidad se consideraba como algo inherente a su condición, casi "como un morbo en la psicología de la realeza que empuja a la clandestinidad con fuerza imperiosa". Es por ello que se describe la conducta de

107 Alejandro Pérez Lugin, "Notas de un reporter. La vida que hace un rey", en El Heraldo de Madrid, junio 29 de junio de 1917

108 Una escenificación similar ya fue utilizada en 1872 para describir el "modestísimo salón" de los saboyanos, propio de personas "nada más que regularmente acomodadas", lleno de libros visiblemente "manoseados" que demostraban la búsqueda continua "de ciencia e ilustración". Manuel Zapatero Garcia, Mi viaje a Italia hecho por la Comisión nombrada por las Cortes Constituyentes con el fin de ofrecer la Corona de España a S.A.R. el Duque de Aosta, Imp. de M. Minuesa, Madrid, 1870, p. 42

109 Cita del diario valenciano El Pueblo de Jordi Luengo López, "Tenorios amanerados. Una lectura queer de la desmitificación del donjuanismo", en Lectures du genre, Lectures théoriques, approches de la fiction. http://lecturesdugenre.fr/lectures_du_genre_5/Luengo.html。5 (2008), pp. 49-76 
Alfonso XIII como fruto de su "desenfado manolesco", siendo muchas las "anécdotas que sin malicia pueden contarse hasta en palacio"110.

\subsection{Victoria de Battemberg: el envoltorio moderno para la feminidad tradicional}

Si el rey adquiere en la representación monárquica el papel de agente de cambio y modernización que hemos señalado anteriormente, las reinas consortes se convierten en el paradigma de orden y estabilidad. Su inclusión en el proyecto nacional pasa por su plena identificación con la maternidad que da sentido a su vida privada y también pública, como esposas de reyes. Sus atribuciones ni siquiera están tipificadas en las constituciones del siglo XIX, que prohíben expresamente el ejercicio de funciones constitucionales al esposo de una reina, pero que no hacen ninguna referencia a ellas, ya que era impensable que una reina consorte tuviera alguna pretensión en ese sentido ${ }^{111}$. Bajo su aparente irrelevancia politica se convierten en la coartada perfecta del rey-hombre, ejemplar esposo y padre de familia, capaz al mismo tiempo de encabezar los destinos nacionales. Se consolida de esta forma un equilibrio familiar fundamentado en "la oposición entre el universo público, masculino y los mundos privados, femeninos"112 y la identificación de la institución con una ciudadanía cuyo ideal familiar sigue esos mismos parámetros.

Existe un "modelo universalmente reconocido de amor y devoción familiar" que ya en 1830 representa a la perfección la reina María Amelia, casada con Luis Felipe de Francia ${ }^{113}$. La esposa de Alfonso XIII, Victoria de Battemberg, personifica igualmente el triunfo de la domesticidad en una institución de la que forma parte pero que no protagoniza. Desde su boda (enamoramiento, preparativos, ceremonia) hasta el nacimiento de su primer hijo, la vida de la reina es narrada con todo lujo de detalles. Sin embargo, cumplida su función maternal, deja paso al rey como protagonista absoluto. En los momentos de crisis de la institución, como 1924, la monarquía española adquiriere "un perfil más familiar" en la opinión pública ${ }^{114}$. El objetivo es impulsar la cuestionada figura de un monarca, que tanto en el ámbito político como en el social intenta aparecer siempre como un hombre fuera de lo común.

Si bien los modelos de masculinidad sobre los que se sustenta el rey pueden variar, adaptándose al proyecto nacional que pretende encarnar en cada

110 Arturo Mori, Alfonso XIII. Vida emotiva y genuinamente española de un rey tipico, op.cit., pp.210-212. Vid. Alicia Mira, "La monarquía imposible: Amadeo I y Maria Victoria", en Emilio La Parra (coord.): La imagen del poder. Reyes y regentes en la España del siglo XIX, Sintesis, Madrid, 2011, p. 304

111 Yolanda Gómez Sánchez, "Matrimonios regios y sucesión a la Corona en la constitución de 1978”, en Antonio Torres del Moral y Yolanda Gómez Sánchez (coords.), Estudios sobre la monarquia, UNED, Madrid, p.193

112 Pierre Bourdieu, La dominación masculina, Anagrama, Barcelona, 2000, p. 76

113 Jo Burr Margadant: "Les représentations de la reine Marie-Amélie dans une monarchie " bourgeoise ", en Revue d'histoire du XIX siècle , op.cit., p.93

114 Julio Montero Diaz, María Antonia Paz y José J. Sánchez Aranda: La imagen pública de la monarquía. Alfonso XIII en la prensa escrita y cinematográfica, Ariel, Barcelona, 2001, pp. 53 y 21415 
momento ${ }^{115}$, el estereotipo de reina consorte se mantiene prácticamente inalterable en el tiempo, siguiendo la estela que en su momento inició $\mathrm{M}^{\mathrm{a}}$ Victoria de Saboya116. Ella fue la "mujer virtuosa, buena madre y benefactora sin igual"117 y también su sucesora austriaca, $\mathrm{M}^{\mathrm{a}}$ Cristina de Habsburgo, ejemplo de la "abnegación, de la virtud y de la sencillez de una madre y de una esposa"118, así como su nuera, Victoria Eugenia, que con las lógicas variaciones en el discurso derivadas de la necesaria incorporación de prácticas acordes con los nuevos tiempos, se consideró ante todo "soberana y madre", aclamada como "reina buena, hermosa y caritativa"119. Son valores que en tiempos recientes han definido a la reina Sofia de Grecia, cuya figura ha sido exaltada, además, como "pacificadora y mediadora en la familia" en los momentos más críticos para la imagen de la monarquía española ${ }^{120}$ y continúan fundamentando las funciones de su sucesora Letizia, "madre además de reina", que con una "agenda oficial propia, separada de la de Felipe VI", demuestra que también es una "mujer real, madre ejemplar y esposa cariñosa"121.

Esta supuesta inalterabilidad en el modelo de reina consorte en ocasiones también presenta ligeros matices derivados de la propia personalidad de estas mujeres, que en algunos momentos pueden trastocar e incluso distorsionar la imagen de la institución. En su momento, la influencia política de María Victoria de Saboya fue el argumento utilizado para criticar la debilidad de un rey que actuaba al dictado de su esposa ${ }^{122}$. Igualmente, en el contexto de la I Guerra Mundial, la imagen oficial de dos reinas, Victoria de Battemberg y Cristina de Habsburgo, que superaban sus diferencias apoyándose en "los rigurosos deberes de su elevadísimo rango, en el amor a la persona del Rey y en su cristiana aceptación de la adversidad"123, no pudo evitar que aflorara públicamente la rivalidad entre ambas. La austriaca suegra gris y austera frente a la nuera inglesa, joven y moderna. La supuesta armonía familiar mostraba así sus grietas ante la "vergonzosa y vergonzante neutralidad" que "a toda costa y trance" mantiene la hausburgiana" y la amargura de la reina Victoria que "ha llorado

115 Anne-Marie Shon, "Sois un homme ! ". La construction de la masculinité au XIXe siècle, Seuil, Paris, 2009

116 Vid. Rosa Ana Gutiérrez Lloret y Alicia Mira Abad: "Ser reinas en la España Constitucional. Isabel II y María Victoria de Saboya y los discursos sobre la legitimación y deslegitimación simbólica de la monarquía nacional" en Historia y politica, 2014, pp. 139-166

${ }^{117}$ Giovanni Battista Conso, Cenni biografici di S.A.R. Maria Vittoria duchessa d'Aosta già regina di Spagna. Turín, Tip. Ed. G. Candeletti, 1877, p.67

118 Mónica Moreno Seco: María Cristina de Habsburgo, la (in)discreta regente en Emilio La Parra López (coord.): La imagen del poder. Reyes y regentes en la España del siglo XIX, Sintesis, Madrid, 2012, p. 397

119 El Imparcial, 14 de febrero de 1918

120 El Pais, 26 de octubre de 2013

121 El Mundo, 19 de diciembre de 2014 y http://www.ellookdelasfamosas.es, 26 de diciembre de 2014

122 Vid. Mónica Moreno Seco y Alicia Mira Abad, Género y negación de la legitimidad monárquica: los republicanos y las reinas, Universitat de València, València,pp.233-254.

$123 A B C, 16$ de abril de 1969. El periódico monárquico realiza unos apuntes biográficos de Victoria de Battemberg con motivo de su fallecimiento, extractados de los escritos del Conde de Romanones. 
mucho durante estos cuatro años", "rodeada, como todos nosotros, de todas las asechanzas y todas las amarguras que el dolor del vencimiento, en determinados momentos, produjo"124.

Al igual que con el monarca, el físico de las reinas consortes permite resaltar sus virtudes morales, aunque en ocasiones la belleza femenina se convierte en un arma de doble filo, que puede llegar a obnubilar la razón de todo un emperador como Napoleón III, cuya esposa, Eugenia de Montijo, es ejemplo de "cómo pierden la corona y la dicha ciertas personas que al marido dan malos consejos" 125 . Pero en general es un atributo exaltado para reforzar la idea de subordinación y pasividad frente a la masculinidad del esposo ${ }^{126}$. El "pudor recatado"127 de la esposa de Amadeo era signo de virtud y de equilibrio correspondiente a una "reina elegida"128, cuyo rostro traduce la "belleza del alma"129, frente al rostro "franco, juvenil, gallardo, grave y apuesto" de su marido Amadeo"130. Mercedes de Orleans "bien merece ser reina porque es más hermosa que las perlas y más buena que el pan", además con su inteligencia y su instrucción "personifica el ideal que los más entusiastas monárquicos desean de una Reina"131. M Cristina de Habsburgo, "si no es guapa, con arreglo a ciertos cánones estéticos, es más que guapa según los eternos cánones morales"132. Unas alusiones a la belleza que criticarán los republicanos para quienes la reina viuda "ni es hermosa ni tal vez tenga ganas de serlo, pues a las madres no les preocupa gran cosa el parecer bonitas"133. En cambio Victoria de Battemberg es "ingenua, sonrosada, bellísima", una "esbelta hada", "como rayo de luz de una alborada"134, una mujer que "siendo o no siendo reina es una reina de la hermosura"135, cuya imagen se transforma con los años en "alta figura repleta y matronil"136.

124 "Discurso de Miguel de Unamuno y mensajes de adhesión al banquete ofrecido a Cávia, Galdós y Unamuno como protesta a la censura gubernamental”, en Los Aliados, 19 de octubre de 1918.

125 El Liberal de 31 de mayo de 1906

126 George L. Mosse, La imagen del hombre. La creación de la masculinidad moderna, op.cit., p.91

127 Gigi Speroni, Amadeo de Saboya rey de España, Barcelona, 1989, p.50

128 Real Biblioteca II- 4040 (caja) 115; Ventura García Barberá, A nuestros serenísimos reyes D. Amadeo y $D^{a}$ María Victoria con motivo de la venida de ésta a España. 21 de marzo de 1871 , Valencia, p. 1

129 Real Biblioteca II- 4040 (caja) 106; Inocencio Pérez Andrés: A su majestad la Reina en celebridad de su llegada a esta Corte (s.a.)

130 Entrada triunfal de D. Amadeo I en Barcelona, Imp. de Luis Fiol, Barcelona, 1871

131 Ana de Sagrera: La Reina Mercedes, op.cit., p. 295-96

132 Julián Cortés Cavanillas, María Cristina de Austria, madre de Alfonso XIII, Aspas, Madrid, 1944, p. 16

133 El Pueblo, 3 de enero de 1898

134 La Publicidad, 29 de mayo de 1906. Gabriel Enciso Núñez, A S. M. Don Alfonso XIII con motivo de su enlace con S.M. la reina Doña Victoria, Madrid, 1906, pp. 1 y 2.

135 El liberal, 26 de mayo de 1906

136 Melchor Almagro San Martín, Ocaso y fin de un reinado. AlfonsoXIII. Los reyes en el destierro, ed. Afrodisio Aguado, Madrid, 1947, p. 149 
Pero Victoria en ocasiones también ofrece la imagen de mujer trasgresora137 (aunque solo fuera en los usos y costumbres de la corte o en su forma de vestir) que a su vez convive con la de esposa y madre abnegada, cuya actuación pública se centra en obras benéficas como había ocurrido con sus antecesoras. Exaltada como "mujer providencial que Dios mismo nos manda para la regeneración de España y "piedra angular donde han de apoyarse las futuras grandezas"138, la prensa pronto la convierte en "modelo de reinas modernas" capaz de cambiar la "tiesura y el ceremonial" que separa la corte de la sociedad. Ena, el nombre por el que la conocen sus más allegados, es ya un signo de "plácida familiaridad", de "gustos sencillos", de "trato exquisitamente llano"139. Al llegar a España "su primer saludo, después de los saludos de familia, fue para el pueblo", representado por "honrados ciudadanos" que con "su tez tostada por el sol y las manos endurecidas por el manejo del arado", destacaban por encima de "la pedreria de las joyas que completaban el tocado" de las grandes damas que fueron a recibirla ${ }^{140}$. En su esmerada educación, supervisada por la propia reina Victoria, sobresalian facetas como música, artes plásticas, ópera, botánica, jardinería y una gran afición a los "sports", especialmente la equitación, por la buena influencia que estos tienen para la salud y la moral ${ }^{141}$. Sentía pasión por los coches y la velocidad al igual que el rey, hasta el punto que éste le pedia en una de sus cartas que no corriera tanto ${ }^{142}$. Fumaba públicamente, llevaba pantalones e incluso "utilizaba colores claros para vestir"143. Las descripciones encajan en muchos aspectos con la imagen de Eva moderna "un nuevo tipo de mujer joven que se mostraba liberada y sin miedo a la crítica social, que fumaba, bebía alcohol y se maquillaba en público; conducía, practicaba deportes como el tenis y el golf"144. Como señala Yuval-Davis el atuendo de las mujeres y su comportamiento ayuda a definir las fronteras de una $\operatorname{colectividad}^{145}$ y en la España de principios de siglo se buscaba ampliarlas respirando aires nuevos. Victoria y sus damas se convirtieron en "maniquies preclaros que en San Sebastián, en Santander y en Madrid señalaban normas y trazaban direcciones". Una nueva inspiración para las aristócratas españolas y las burguesas que "comenzaron a hacerse elegantes y a europeizarse en sus costumbres", en una

137 Nerea Aresti Esteban, "La mujer moderna, el tercer sexo y la 'bohemia en los años veinte", Dossiers Feministes, 10, (2007), pp.173-1 85.

138 Nuevo Mundo, 24 de mayo de 1906

139 La correspondencia de España, 29 de mayo de 1906

140 El liberal, 26 de mayo de 1906

141 Nuevo Mundo, 24 de mayo de 1906

142 Postal fechada en diciembre de 1905. Marino Gómez Santos, Correspondencia epistolar de la princesa Victoria Eugenia de Battemberg al rey Alfonso XIII, Madrid, 1993, p. 24 p. 170

${ }_{143}$ Ángeles Hijano, Victoria Eugenia de Battemberg. Una reina exiliada, Aldebarán, Madrid, 2000,

144 Nuria Rodríguez Martín, “Jóvenes, modernas y deportistas: la construcción de nuevos roles sociales en la España del primer tercio del siglo xx a través de la publicidad", en Encarna Nicolás y Carmen González (edits.), Ayeres en discusión. Temas claves de Historia Contemporánea hoy, Editum, Murcia, 2008.

145 Nira Yuval-Davis, "Nationalist Projects and gender relations", op.cit. p.16 
Corte que había sido "triste, casi monástica"146. Tras el "pesimismo del 98" el "tono ameno de los coloridos" y el "afán de diversión" representaban un signo de cambio ${ }^{147}$. Era además "la reina de los Deportes", una auténtica "sportswoman" que practicaba el "deporte de la agricultura"148. En este sentido se la consideraba una activa "promotora del feminismo agrícola entre las damas de nuestra buena sociedad", debido a su amor por el campo relacionado con "un movimiento que en Inglaterra se llama "Back to the land", abanderado por la condesa de Warwick, "hermosa, alta y riquísima", quien fundó "en el castillo de Sutdley una escuela donde más de sesenta señoritas labran la tierra". Victoria, antes de convertirse en reina ya habia mantenido contactos en este sentido con damas españolas como Emilia Pardo Bazán a través de varias publicaciones internacionales. Los efectos benéficos de esta empresa eran además del agrado del rey que siempre "ha manifestado su aspiración a ser el primer agricultor de España"149.

Al igual que Alfonso XIII el modelo de feminidad que proyecta la reina Victoria debia conectar con las viejas esencias hispanas. Es cierto que su origen inglés, se consideraba como un faro regenerador en el sombrío panorama político y social hispano, pero también podía levantar suspicacias entre los sectores más conservadores. Ya antes que ella, $\mathrm{M}^{\mathrm{a}}$ Victoria de Saboya y su suegra, María Cristina de Habsburgo, se esforzaron por ganar apoyos en la Corte porque no eran españolas. La primera debido a su escaso pedigrí monárquico y por ser la esposa de un rey con un talante excesivamente democrático ${ }^{150}$ y la segunda, porque su austeridad no encajaba bien con el carácter del pueblo español que criticaba "su fanatismo y rigidez de mujer del Norte" en contraste con los españoles, "alegres, animosos y zumbones, que la llamaban María la Seca"151.

La fascinación por Inglaterra que encarnó la reina Victoria desde su boda es patente en muchos aspectos. "La recién venida" poseía "el encanto misterioso y poético de la princesa lejana. Así "los mismos que abominan de soberanias personales, se inclinan afectuosos y corteses ante la diadema de sus cabellos rubios"152. Acorde con esa atracción se produjo una especie de "inglesización" del lenguaje patente en las descripciones de los actos protagonizados por los reyes. Desde el noviazgo los periódicos hablaban de los "sports" que practicaba la pareja, el "pudding cake" de la boda153 o la concurrida "garden party" que tuvo lugar en Barcelona en 1908 con motivo de la visita del matrimonio regio ${ }^{154}$.

146 Covadonga López Alonso (edit.), Doña Eulalia de Borbón Infanta de España, Memorias, Castalia/ Instituto de la mujer, Madrid, 1991, pp. 229-242

147 Arturo Mori, Alfonso XIII 1886-1941. Vida Emotiva y genuinamente española de un rey típico, op.cit., p. 149

148 El Imparcial, 7 de mayo de 1906

149 La correspondencia de España, 27 de mayo de 1906

150 Ana de Sagrera, Una rusa en España: Sofía, duquesa de Sesto, Espasa-Calpe, Barcelona, 1990, p. 162

151 Mónica Moreno y Alicia Mira, "Género y negación de la legitimidad monárquica”, op.cit.,, p. 248

152 El liberal, 26 de Mayo de 1906

153 El liberal del 31 de mayo de 1906

154 Nuevo Mundo, 20 de octubre de 1908. También El liberal, 13 de mayo de 1907 
Palabras que contrastaban con la imagen de los españoles "chulos y de majas de pandereta que pasean por los escenarios extranjeros"155.

Pero su españolización era necesaria y empezó con las corridas de toros, a las que acudía con el atuendo típico: "blanca mantilla", prendidos "claveles frescos y olorosos", "rojos y amarillos, los colores nacionales -de su bandera". E1 pueblo "aclama con entusiasmo a su Reina, al ver que para realzar su espléndida belleza en la fiesta española, se adorna a la española", resaltando así "su triunfo como mujer y como reina"156. A pesar de su amor incondicional por la tortilla de patatas ${ }^{157}$, siempre acabó prevaleciendo su imagen de mujer fría y distante, excesivamente preocupada por su atuendo y joyas, escasamente afín con las tradiciones españolas, en consonancia con el estereotipo de la flema inglesa.

Tampoco la religión ayudó mucho a la princesa inglesa. La católica España acogía como reina a una protestante. Aunque oía misa "con verdadero recogimiento" 158 , la cuestión no se limitaba solo a escenificar la fe. El tema religioso ya había sido un problema para María Victoria de Saboya, que a pesar de su devoción católica no pudo hacerse perdonar que era nuera de Víctor Manuel $\mathrm{II}^{159}$. En el polo opuesto la religiosidad de María Cristina de Habsburgo fue un aspecto criticado por los sectores anticlericales que señalaban la excesiva influencia del clero sobre la reina ${ }^{160}$. Pero Victoria de Battenberg iniciaba su camino como reina consorte con una conversión ${ }^{161}$. La teatralización del acontecimiento fue preparada con rapidez y cautela. Alfonso XIII aseguraba a Pio $\mathrm{X}$ "que no han sido motivos de violenta coacción o razón de Estado los móviles" que obligaban a su prometida a "abandonar el error" y el papa respondió con su absoluta confianza en el "vivísimo entendimiento y fina voluntad" de la futura reina. Estaba en juego la imagen popular de la princesa en España y por ende de la monarquia, que trataba de evitar a toda costa un enfrentamiento clerical, sin herir la "susceptibilidad de los protestantes británicos". De hecho El Motín, periódico satírico anticlerical, hablaba del Battenberqueo", refiriéndose a los sectores ultracatólicos que "ponían a los ascendientes de la reina como un trapo" y entre ellos a la "mayor parte de los curas y los frailes de Madrid que omiten en la misa mayor la oración pro regina"162. Los recelos religiosos también llegaron al propio rey Eduardo VII, tío de la novia, que deseaba que la ceremonia de conversión se desarrollara en París y no en España. Finalmente se optó por un acto en el que se evitaría "todo aparato" en el "palacio de la augusta madre del rey y en su presencia”. Así la nueva "hija sumisa de la Iglesia Apostólica y Romana"

155 La Correspondencia de España, 25 de mayo de 1906

156 Pedro Marroquín Aguirre, Amor a España, Méjico, 1911. p.49, 102-103; El Imparcial, 3 y 7 de junio de 1906

157 “Álbum biográfico de doña Victoria Eugenia”, en Miss, 4 de abril de 1969

158 La Correspondencia de España, 28 de mayo de 1906

${ }^{159}$ Bonifacio Carrasco de Campos, Oda a la reina $M^{a}$ Victoria, Madrid, 1871, p. 14

160 Mónica Moreno Seco, "María Cristina de Habsburgo, la (in)discreta regente" en Emilio La Parra (coord..) La imagen del poder. Reyes y regentes en la España del siglo XIX, Sintesis, Madrid, 2011 , p. 391

161 Vid Ángeles Hijano Pérez "Conversión al catolicismo de una princesa protestante" en Estudios Eclesiásticos, 75, (2000), pp. 541-561

162 El Motin, 8 de octubre de 1906 y 25 de febrero de 1909 
entró al catolicismo vestida "toda de blanco, con mantilla blanca, pálida, emocional, recogida y humilde, con un aspecto angelical" 163 .

Tras el evento las muestras de religiosidad regia quedaron vinculadas a las obras de caridad. Mientras el rey despachaba asuntos de Estado o se pasaba el día cazando ${ }^{164}$, la reina, "cumplida su misión de reina y madre", desarrollaba sus deberes con actividades benéficas variadas: el proyecto de "El barrio obrero Reina Victoria", la promoción del Ropero de Santa Victoria, las visitas a los asilos o la fundación, "por su generosa iniciativa", de los comedores de caridad para repartir comida acompañada de su "alto séquito" fueron algunas de las actividades más destacadas por la prensa junto al impulso a la Cruz Roja165.

Pero la función más importante de una reina es la continuidad dinástica ${ }^{166} \mathrm{y}$ Victoria de Battemberg cumplió su cometido "disciplinadamente", dedicándose "a parir una vez al año, con el único objetivo de conseguir la descendencia suficiente"167. La "Gaceta" anunciaba periódicamente el proceso de los embarazos de la reina, "que formaban parte, en espíritu y en materia, de la buena marcha de la Constitución española". En realidad "las campanas de los bautizos apagaban un poco el sombrío panorama de España"168. Su primer alumbramiento incrementó la popularidad de la corona en una prensa empeñada en retratarla como una madre española cualquiera, que se ocupaba personalmente de la crianza de sus hijos ${ }^{169}$. Precisamente la lactancia se convirtió en un aspecto de interés nacional, exaltándose la naturalidad frente a los artificios de la Corte ${ }^{170}$, algo que ya había ocurrido con $\mathrm{M}^{\mathrm{a}}$ Victoria de Saboya, modelo ternura maternal 171. "La madre española" a diferencia de las de otros países "estima como desgracia inmensa verse obligada" a renunciar a "ese sagrado deber de la lactancia, impuesto por la amorosa maternidad". Si llega el caso, la madre reconoce "su inferioridad y se conceptúa de peor condición que todas sus compatriotas porque es gala de la mujer española criar a los frutos de su cariño". Victoria de Battemberg, española por su enlace Alfonso XIII, ve refrendado su "españolismo" con el nacimiento del príncipe de Asturias, pero ante el "publico femenino" necesita "confirmación definitiva de esa carta de naturaleza" a través de la asimilación, "con noble espontaneidad, de nuestros usos y costumbres". Sin embargo, a pesar de un organismo "pletórico de salud y robustecido por el

163 Archivo General de Palacio. Reinados. Alfonso XIII. 12.911/24; 15.681/10;1402/3

164 El Día, 4 de diciembre de 1916

165 El Imparcial 29 de mayo de 1906; 5 y 19 de febrero de 1913; “28 de enero y 14 de febrero de 1918

166 Clarissa Campbell Orr, "Introduction" a Queenship in Europe, 1660-1815. The role of the consort, Cambridge University Press, Cambridge, 2004, pp. 5 y 12.

167 Ángeles Hijano, Victoria Eugenia de Battemberg. Una reina exiliada, op.cit., p. 113

168 Arturo Mori, Alfonso XIII 1886-1941. Vida Emotiva y genuinamente española de un rey tipico,op.cit., pp.107 y 151

169 El Imparcial, 10 de mayo de 1907

170 Mónica Bolufer, "Actitudes y discursos sobre la maternidad en el siglo XVIII: la cuestión de la lactancia, Historia Social, 14, (1992), p. 8

171 Ana de Sagrera, Amadeo y María Victoria. Reyes de España 1870-1873, Palma de Mallorca, 1959, pp. 224-226 Benito Pérez Galdós, Amadeo I. Episodios Nacionales, Historia 16, Madrid, p. 194. 
equilibrio perfecto de la raza anglosajona", sus deseos se estrellaron "contra el inflexible mandato de la Ciencia" y Victoria desgraciadamente:

¡no criará a su augusto hijo! ¡El príncipe de Asturias no beberá los jugos de la vida en el materno seno! (....) ¡Pobre madre! Sin ser un lince en psicologías mayestáticas (la reina envidia) a todas las madres que pueden consagrarse a la lactancia de sus hijuelos"172.

\section{CONCLUSIONES}

Como cualquier otro discurso para legitimar la monarquía, el español vincula a la institución con un proyecto de nación que une el pasado, el presente y el futuro en una narrativa identitaria reconocible para la ciudadanía. A principios del siglo XX la idea de regeneración se impone frente a la de revolución como opción de cambio. En este contexto el joven rey Alfonso XIII personifica la unidad nacional, de manera que su matrimonio se convierte en un aspecto crucial para proyectar unos valores de cohesión social, de continuidad y de estabilidad. Sin embargo, el monarca y su esposa no representan una imagen estática. El desempeño de sus respectivos papeles se convierte en el alimento básico de una narrativa legitimadora viva, en constante construcción, cuyos ingredientes se mueven en una especie de pulsión sin fin entre lo puramente gestual, aparentemente espontáneo y cercano, y la tradición, supuestamente inamovible. En el teatro regio ambos encarnan papeles distintos pero complementarios, en una trama que incorpora o expulsa elementos en función del propio devenir social.

Los resortes legitimadores que intervienen en ese discurso no son nuevos. A lo largo del siglo XIX todas las monarquías contemporáneas, con sus matices e intensidades, han desarrollado nuevas fuentes de legitimidad cuyos componentes se mueven entre la cercanía popular y un aspecto mayestático inherente a la institución. De manera que el perfil público de las personas regias adquiere una gran relevancia como objeto de análisis y la construcción de los estereotipos que proyectan, dentro de la unión matrimonial, se convierte en un aspecto crucial para comprender los avances y las pervivencias en el discurso monárquico. El objetivo es compactar voluntades, crear emociones, convertirse en referente identitario sobre un postulado inquebrantable: el poder de la persuasión circula en doble dirección a partir de un mecanismo de retroalimentación, es decir, las salidas del sistema, regresan al mismo como recursos o información. La construcción de verdades coherentes en este bucle requiere por tanto de una escenografía adecuada, dinámica pero que a la vez transmita estabilidad y eficacia para atraer muchos y variados ojos. En torno a la figura del rey y de la reina se construye una privacidad pública a partir de retazos de vida convenientemente ensamblados para avivar su popularidad y consolidar la institución que personifican. Su impacto se hace especialmente evidente en momentos en los que es necesaria una resignificación del poder monárquico y de la nación.

En una época de crisis de las viejas esencias ¿qué impulso regenerador y nacionalizador puede aportar una institución que procede de otro tiempo y que

\footnotetext{
${ }^{172}$ El Imparcial, 21 y 30 de mayo de 1907.
} 
representa la tradición y las viejas costumbres? El matrimonio regio fue en su momento la respuesta a esta cuestión al presentarse como el punto de intersección entre lo nuevo y lo viejo; el inicio de una nueva vida, la renovación, el cambio necesario y esperado, pero acometido dentro de los cauces del orden y la estabilidad inherentes a la monarquía. Su relato respondia a una producción ritualizada que no necesariamente constituía el fiel reflejo de la cotidianeidad de los ciudadanos y las ciudadanas a quienes va dirigido; pero su eficacia residia precisamente en la capacidad para proyectar sus expectativas e ideales. El rey moderno, siempre conocedor de las vanguardias y de los últimos avances del progreso, al mismo tiempo guardián de las esencias españolas e imagen del perfecto ciudadano y padre de familia. La reina compañera, pero ante todo madre, equilibraba el dinamismo masculino fijando con los valores atribuidos a su feminidad el objetivo de la cámara, ante las exigencias de una realidad cambiante a la que tenía que adaptarse una institución que pretendia erigirse en el principal eje de identidad nacional. Sin embargo, la imagen del matrimonio regio solo fue un revoco en la fachada nacional. Su utilización como representación del cambio o de la estabilidad era limitada y su desgaste fue evidente en los momentos de crisis. La monarquía alfonsina evidenciaba la ausencia de un proyecto nacional hegemónico.

Fecha de envío / Submission Date: 2/11/2015

Fecha de aceptación / Acceptance Date: 15/01/2016 